\section{Critical Evaluation of Stability Constants of Metal Complexes of Complexones for Biomedical and Environmental Applications (IUPAC Technical Report)}

\author{
Giorgio Anderegg, Françoise Arnaud-Neu, Rita \\ Delgado, Judith Felcman, and Konstantin Popov \\ Pure and Applied Chemistry \\ Vol. 77, No. 8, pp. 1445-1495 (2005)
}

This study involves evaluation of all reported proton and metal ion binding constants for the remaining commonly used complexones, and the identification of recommended values for use in chemical speciation calculations. Within these objectives, a priority was given to compounds of strong medical and environmental importance and to those (IDA and MIDA) that represent complex-forming fragments and decomposition products of higher denticity complexones.

Within a broad variety of applications, complexones have in common the regulation of metal concentrations in widely differing systems. Complexones are used in detergents, textile and paper processing, photographic developing solutions, scale solubilization in processing tanks, electroplating, and as components of agricultural micro-fertilizers. Annual industrial output of EDTA and other complexones in the thousands of tons.

This paper presents critical evaluations of available experimental data, published between 1945-2000, on stability constants of proton (hydron) and metal complexes for seven complexones of particular biomedical and environmental interest: iminodiacetic acid [2,2'azanediyldiacetic acid, IDA], (methylimino)diacetic acid [2,2'-(methylazanediyl)diacetic acid, MIDA]; 2,2 ',2",2"'-\{[(carboxymethyl)azanediyl]bis[(ethane1,2-diyl)nitrilo]\}tetraacetic acid (DTPA), 3,6,9,12tetrakis(carboxymethyl)-3,6,9,12-tetraazatetradecane dioic acid (TTHA); 2,2',2"-(1,4,7-triazonane-1,4,7triyl)triacetic acid (NOTA); 2,2',2",2"'-(1,4,7,10tetraazacyclododecane-1,4,7,10-tetrayl)tetraacetic acid (DOTA); 2,2',2",2"'-(1,4,8,11-tetraazacyclotetradecane-1,4,8,11-tetrayl)tetraacetic acid. Some typical errors in stability constant measurements for particular complexones are summarized. Higher quality data are selected and presented as "Rec-ommended" or "Provisional."

\section{www.iupac.org/publications/pac/2005/7708/7708x1445.htm}

\section{Round Robin Test on the Molecular Characterization of Epoxy Resins by Liquid Chromatography}

\section{Stepan Podzimek \\ International Journal of Polymer Analysis and Characterization \\ Vol. 9, No. 5-6, pp. 305-316 (2004) \\ DOI: $10.1080 / 10236660490935718$}

The great importance of epoxy resins originates from the wide range of applications in many industrial areas. However, only relatively primitive analytical tests are commonly used for routine characterization of epoxy resins. The simple characteristics are often unable to discriminate among different samples, to find structure versus properties relations, and to evaluate production reproducibility. Molar mass distribution of epoxy resins affects their application properties and can be also used as a sensitive measure of the reproducibility of the production.

The main objectives of this project were (i) to study the influence of experimental conditions, in particular the type and number of columns and column calibration, on the molar mass averages obtained by size exclusion chromatography (SEC), and (ii) to figure out attainable reproducibility of SEC results generated in different laboratories, and (iii) to compare SEC molar mass averages with those determined by the absolute methods. Since epoxy resins are typical examples of oligomers, most of the conclusions may be generally applicable to the analysis of other oligomers.

Two commercially available epoxy resins based on bisphenol A (2,2-bis(4-hydroxyphenyl)propane) of different molar mass distribution were selected for the Round Robin Test. The samples were characterized by vapor pressure osmometry (VPO), method of end groups (EG), multi-angle light scattering (MALS) in batch mode, and matrix assisted laser desorption ionization mass spectroscopy (MALDI-MS) to allow comparison of chromatographic results with the data from the absolute methods of molar mass determination.

\section{www.iupac.org/projects/1999/1999-021-1-400.htm}

